\title{
Caracterização demográfica das populações de cães e gatos supervisionados do município de São Paulo
}

[Demographic characterization of supervised dog and cat populations in Sao Paulo city, Brazil]

B.D. Canatto ${ }^{1}$, E.A. Silva ${ }^{2}$, F. Bernardi ${ }^{2}$, M.C.N.C. Mendes ${ }^{2}$, N.T. Paranhos ${ }^{2}$, R.A. Dias ${ }^{1 *}$

${ }^{1}$ Faculdade de Medicina Veterinária e Zootecnia - Universidade de São Paulo - São Paulo, SP

${ }^{2}$ Centro de Controle de Zoonoses - Secretaria Municipal de Saúde - Prefeitura de São Paulo, SP

\section{RESUMO}

A caracterização das populações canina e felina domiciliadas do município de São Paulo (SP) foi realizada utilizando-se amostragem complexa com seleção aleatória em dois estágios. Em cada distrito administrativo, foram visitados seis setores censitários e 20 domicílios em cada setor sorteado, de setembro de 2006 a setembro de 2009, totalizando 11.272 entrevistas. A razão homem:cão foi de 4,34, e a razão homem:gato de 19,33. A população canina foi estimada em 2.507.401, e a felina em 562.965. A população canina era composta por $52,7 \%$ de machos, e a felina por $45,1 \%$. A proporção de fêmeas esterilizadas, $23,4 \%$ das cadelas e $46,1 \%$ das gatas, é maior que a de machos, $11,4 \%$ dos cães e $31,5 \%$ dos gatos. A idade média dos cães era de 4,99 anos e a dos gatos de 3,53 anos. A proporção de cães com restrição de acesso à rua, $64,4 \%$, foi maior que a de gatos, 42,5\%. A média de animais/domicílio foi estimada em 1,60 para cães e 1,69 para gatos. A guarda destes animais está associada a fatores culturais, assim a caracterização da população de animais é base da estruturação adequada de programas de controle populacional e de zoonoses.

Palavras-chave: cão, gato, zoonose, controle populacional

\begin{abstract}
This study aimed to estimate the owned dog and cat populations of São Paulo city using a complex sample with random selection in two stages. In each administrative district, six census sectors and 20 households in each sampled sector were visited from September 2006 to September 2009, totalizing 11,272 interviews. The human:dog ratio was 4.34 and the human:cat ratio was 19.33. The dog population was 2,507,401 and the cat population, 562,965. The dog population was composted of 52.7\% males, while among the cat population it was $45.1 \%$. The proportion of sterilized females $(23.4 \%$ among dogs and $46.1 \%$ among cats) was higher than males (11.4\% among dogs and $31.5 \%$ among cats). The mean age of dogs was 4.99 years, and for cats, 3.53 years. The proportion of restricted (without access to the street) dogs, $64.4 \%$, was higher than restricted cats, $42.5 \%$. The average number of animals/household was 1.60 for dogs and 1.69 for cats. The animal ownership is associated with cultural factors, therefore the characterization of canine and feline population is essential to implement an adequate animal population management program and zoonosis control.
\end{abstract}

Key words: dog, cat, zoonosis, population control

\section{INTRODUÇÃO}

Cães e gatos afetaram diretamente o desenvolvimento da espécie humana, uma vez que sua domesticação se iniciou no mesmo período em que o homem passou a desenvolver

Recebido em 5 de setembro de 2011

Aceito em 20 de julho de 2012

*Autor para correspondência (corresponding author)

E-mail: dias@vps.fmvz.usp.br relações de grupo. Desta forma, urbanização e domesticação têm muito em comum e são indissociáveis (Beck, 1973). Com a convivência simbiótica entre as espécies, desenvolveram-se usos específicos dos cães e gatos pelo homem (Who, 1990): (a) animais de trabalho: animais usados para pastoreio ou guarda de outros 
animais e edificações, corrida, caça, guia de cegos ou uso pela polícia ou Exército; (b) animais de companhia: posse somente para companhia ou lazer, sem interação afetuosa mais intensa; (c) animais "pet”: animal de companhia, porém com uma relação próxima e afetuosa com seu proprietário, considerado membro da família.

Mesmo que a seleção destes animais tenha atendido a demandas e necessidades específicas enquanto foram necessárias, atualmente não há uma razão clara para a manutenção destas espécies. Entretanto, a posse de cães e gatos é comum no mundo todo (MacPherson, 2000), intensificando-se a partir dos séculos XVI e XVII, quando a melhoria da qualidade de vida da população humana possibilitou criar animais sem função econômica (Thomas, 1988). O grau de dependência entre as espécies animais e o homem, principalmente no provimento de abrigo, alimento e água, permite classificar as populações de cães e gatos em (WHO, 1990): (a) domiciliadas: totalmente dependentes, restritos e supervisionados por um proprietário; (b) semidomiciliadas: totalmente dependente, semirrestrito, eventualmente classificado como "de família"; (c) de vizinhança: semidependente, semirrestrito ou sem restrição, sob responsabilidade coletiva; (d) feral: independente e sem restrição, embora necessite de sobras para sobrevivência, não possui um responsável, sem interação com humanos.

A maioria dos problemas advindos da convivência com animais em áreas urbanas diz respeito aos cães. Os principais são: danos ambientais, acidentes de trânsito (atropelamentos), transmissão de doenças e mordeduras que, no município de São Paulo, totalizaram cerca de 17.000 notificações (Sinan, 2009). Este dado é especialmente preocupante no Brasil, onde ainda circula a variante 2 do vírus rábico, principal variante antigênica transmitida ao homem pelos carnívoros, sejam eles domésticos ou silvestres, principalmente por meio da mordedura (Favoretto, 2002). Além disso, uma extensa lista de zoonoses pode ser atribuída aos cães e gatos (Plaut, 1996). Embora o contato com animais traga riscos, a frequência da maioria das doenças zoonóticas pode ser reduzida, ou até eliminada, mediante práticas de manejo e políticas públicas. Cuidados veterinários, restrição de movimento, reprodução seletiva, legislação responsável e educação dos proprietários podem fazer da posse de animais uma experiência positiva.

A descrição da população de cães e gatos é importante no sentido de prover a compreensão dos efeitos da urbanização humana. Uma vez que a sua ecologia é descrita, pode ser utilizada como indicador de estresse, poluição, deterioração ambiental e como modelo para adaptações comportamentais à vida urbana (Beck, 1973).

Até 2001, não se conhecia o tamanho da população de animais do município, quando foi realizado um estudo que teve como objetivo caracterizá-la, sem, no entanto, considerar a heterogeneidade da cidade (Paranhos, 2002). Essa preocupação era perfeitamente justificada, e as ações de saúde animal eram planejadas e executadas pelo Centro de Controle de Zoonoses (CCZ), de forma centralizada, até 2002, quando houve a descentralização das ações de saúde no município (BRASIL, 2002). As ações passaram a ser realizadas localmente, em espaços geográficos denominados de Supervisões de Vigilância em Saúde (SUVIS), que agregam os 96 distritos administrativos da cidade.

O objetivo do presente estudo é caracterizar a população de cães e gatos do município de São Paulo, de modo a permitir a estruturação adequada de programas de controle populacional e de zoonoses.

\section{MATERIAL E MÉTODO}

Os distritos administrativos (DA) foram as unidades de caracterização, apesar de haver uma divisão do município em áreas específicas de atenção à saúde, as Supervisões de Vigilância em Saúde (SUVIS), para que não houvesse viés de representação ao longo do tempo (por exemplo, pelo rearranjo das SUVIS).

A heterogeneidade da ocupação do espaço foi considerada na composição da amostra, mediante a estratificação dos setores censitários dos distritos administrativos em três categorias (IBGE, 2000): (a) urbanos comuns: áreas que possuem arruamento implantado; (b) urbanos subnormais: áreas desestruturadas, como favelas, cortiços, ocupações e aldeias indígenas; (c) rurais: áreas que englobam os aglomerados rurais de extensão urbana ou os aglomerados isolados (localizados nas periferias das zonas sul, 
leste e norte). A proporção de cada um destes tipos de setores foi respeitada quando da escolha dos setores que constituiriam a amostra, em cada DA. Os setores especiais, que compreendem quartéis, alojamentos, cadeias, asilos, orfanatos, conventos e hospitais, não foram incluídos na amostra.

Considerou-se domicílio não somente os domicílios residenciais, mas também estabelecimentos comerciais e industriais.

A amostra foi desenhada em dois estágios: (a) no primeiro estágio, foi calculado um número de setores censitários a serem amostrados em cada DA, estratificados em urbanos (comum e subnormal) e rurais, e (b) no segundo estágio, foi calculado um número de domicílios (residenciais, comerciais e industriais) a serem visitados em cada setor. Para isso, foi utilizada a fórmula de estimativa de proporções (Thrusfield, 2007): $\boldsymbol{P}=1,96^{2}\left(\boldsymbol{P}_{\text {esp }}\left(\boldsymbol{1}-\boldsymbol{P}_{\text {esp }}\right) / \boldsymbol{E}^{2}\right.$, em que:

$P_{e s p}=$ proporção esperada de animais no domicílio (utilizaram-se 50\%, de modo a maximizar o tamanho da amostra);

$E=$ erro esperado (utilizaram-se $5 \%$ para a amostra de setores censitários e $10 \%$ para a amostra de domicílios).

Assim, em cada DA, foram aleatoriamente amostrados seis setores censitários, e, em cada um dos setores, 20 domicílios foram visitados. Em cada setor censitário sorteado, foi realizada uma amostra sistemática dos domicílios, ou seja, sabendo-se o número de domicílios existentes em cada setor censitário (IBGE, 2000) e o número a ser visitado, 20, foi respeitado um intervalo entre domicílios a serem escolhidos. $\mathrm{O}$ trajeto percorrido pelo entrevistador foi determinado por um mapa (IBGE, 2000), sendo obrigado a percorrer todas as ruas de um setor censitário escolhido. Os apartamentos foram considerados como "domicílios empilhados", e a contagem do intervalo foi contínua, com base na numeração dos apartamentos. Se no domicílio escolhido não foi encontrado um munícipe ou se houve recusa, procedeu-se à aplicação do questionário em um domicílio imediatamente vizinho.

Foi aplicado um questionário contendo perguntas relacionadas ao tipo de domicílio, objetivo da posse, motivação da posse, local de manutenção dos animais, número de animais, número de pessoas e de animais no domicílio, além de perguntas referentes a cada animal (nome, sexo, idade e forma de aquisição). A forma de aquisição dos animais foi caracterizada como sendo feita com ou sem custo. Considerou-se animal adotado aquele adquirido sem custo, podendo ter sido pego, ter nascido no próprio domicílio, ter sido adotado ou ter sido ganho de presente.

Em cada SUVIS, foram formadas equipes devidamente treinadas pelos coordenadores do projeto para a realização das entrevistas, compostas por, pelo menos, dois agentes de zoonoses. Normalmente, havia duas equipes de campo trabalhando ao mesmo tempo, em cada SUVIS. O trabalho de campo era realizado em dias úteis, em horário comercial. Nas áreas centrais, os domicílios foram visitados aos finais de semana, a fim de reduzir o número de domicílios vazios e recusas. Dado que a adesão das SUVIS foi voluntária, o trabalho de campo, iniciado em setembro de 2006, estendeu-se até setembro de 2009, com uma interrupção entre junho de 2007 e julho de 2008. As informações obtidas foram digitadas em um banco de dados eletrônico que permitia somente a inclusão de dados, impedindo a visualização das tabelas e consultas.

A ponderação utilizada para o cálculo das frequências das variáveis foi calculada em duas fases: (a) inicialmente, calculou-se o número de domicílios representados pela amostra de cada setor, dividindo-se o número de domicílios existentes no setor em questão por 20 (tamanho da amostra de domicílios em cada setor censitário), e (b), posteriormente, o número de domicílios do DA representado pelos domicílios visitados nos seis setores censitários de um referido DA, dividindo-se o número de domicílios do DA pelo número de domicílios visitados nos seis setores censitários do referido distrito.

O tamanho da população de animais foi estimado a partir da razão entre a população humana ponderada (numerador) e o número ponderado de animais (denominador). Dessa forma, a estimativas da população de cães e gatos foi obtida pela divisão da população humana de 2007 (Fundação..., 2009) pelas razões. 
Finalmente, foram realizadas correlações entre as variáveis levantadas neste inquérito com outras variáveis obtidas em estudos contemporâneos (Folha de São Paulo, 2009) e com o índice de exclusão social determinado por Sposati (1996). Foi calculada a correlação de Spearman, com os dados agregados por DA. Foi considerado como nível descritivo das análises o valor de $5 \%$. As análises foram realizadas nos programas de computador SPSS 9.0 e EpiInfo 6.04.

\section{RESULTADOS E DISCUSSÃO}

Este trabalho pode ser classificado como um estudo transversal. Conceitualmente, isto exigiria que as informações fossem coletadas ao mesmo tempo, o que, para um trabalho dessa magnitude, é logisticamente impossível, uma vez que foram visitados 11.272 domicílios. Não houve recusas para a participação nas entrevistas, tanto em áreas mais quanto em áreas menos excluídas socialmente. Nos DA centrais, houve um número significativo de domicílios vazios, mesmo visitando-os nos finais de semana. Tais situações foram solucionadas com a escolha de um domicílio vizinho. Ao se considerar como domicílio todo e qualquer endereço, seja residencial, comercial ou industrial, obteve-se uma estratégia inovadora em estudos desse tipo, uma vez que os trabalhos anteriores (Nunes et al., 1997; Dias, 2001; Paranhos, 2002; Dias et al., 2004; Alves et al., 2005; Magnabosco, 2006; Grisi-Filho et al., 2008) somente incluíram no quadro amostral os domicílios residenciais, ocasionando uma aproximação subestimada da população animal.

A razão homem:cão para o município de São Paulo é 4,34 (IC95\% = 4,22; 4,47), ou seja, existem 4,34 pessoas para cada cão na cidade. Este número variou de 1,46 a 13,58 , nos DA. A razão homem:gato, por sua vez, é 19,33 (IC95\% $=17,86 ; 20,80)$, variando de 6,93 a 70,19, nos DA. Há significativamente mais cães que gatos por pessoa.

Nas áreas urbanas subnormais e rurais, há significativamente menos cães por pessoa, quando comparadas às áreas urbanas comuns, evidenciando a associação entre urbanização e altas densidades demográficas de humanos e cães. Nas áreas urbanas subnormais, há mais gatos por pessoa que nas áreas urbanas comuns. A população de cães e gatos domiciliados nas tipologias de setores censitários estão na Tab. 1.

Tabela 1. Distribuição da população de cães e gatos domiciliados nas tipologias de setores censitários do município de São Paulo, 2011

\begin{tabular}{lrrrr}
\hline \multirow{2}{*}{ Tipologia de setor censitário } & \multicolumn{2}{c}{ Cães } & \multicolumn{2}{c}{ Gatos } \\
\cline { 2 - 5 } & \multicolumn{1}{c}{$\mathrm{N}$} & \multicolumn{1}{c}{ N } & \multicolumn{1}{c}{$\%$} \\
\hline Urbano comum & 2.128 .747 & 84,90 & 435.498 & 77,36 \\
Urbano subnormal & 213.905 & 8,53 & 85.061 & 15,11 \\
Rural & 164.749 & 6,57 & 42.406 & 7,53 \\
\hline Total & 2.507 .401 & 100,00 & 562.965 & 100,00 \\
\hline
\end{tabular}

A razão homem:cão nos domicílios de humanos (apartamentos e casas) é de 4,28 (IC95\% = 4,16; $4,40)$, enquanto para gatos é de 18,98 (IC95\% = $17,51 ; 20,44)$, sendo que ambas não diferem da razão geral para o município. A população total de cães domiciliados no município de São Paulo foi estimada em 2.507.401, e a de gatos em 562.965. As proporções de animais nas tipologias de domicílios estão dispostas na Tab. 2.

Existe correlação positiva entre as populações humanas e caninas absolutas $(r=0,83, \mathrm{P}<0,001)$ e entre as populações humanas e felinas absolutas nos DA $(r=0,76, \mathrm{P}<0,001)$. De forma geral, as maiores populações animais, em termos absolutos, estão localizadas na periferia da cidade, seguindo o padrão de distribuição de humanos (Fig. 1).

Apesar de haver um padrão geográfico na distribuição das populações absolutas de animais, não se observa o mesmo padrão ao se analisar a razão entre populações humana e animal. Há significantemente mais cães por pessoa nas regiões oeste e sul da cidade (Fig. 2a), enquanto para gatos, não há o mesmo padrão geográfico (Fig. 2b). Sabe-se que fatores socioeconômicos, tais como renda e escolaridade, não estão correlacionados com a razão homem:cão e homem:gato (Dias, 2001; Dias et al., 2004; Alves et al., 2005). 


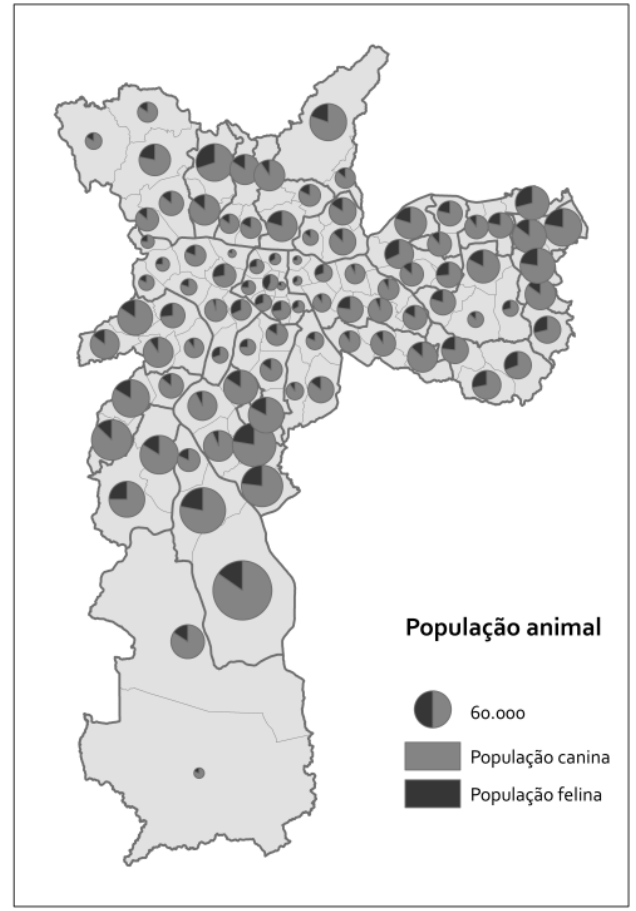

Figura 1. Mapa da participação relativa de cães e gatos na composição da população animal domiciliada nos distritos administrativos do município de São Paulo, 2011.
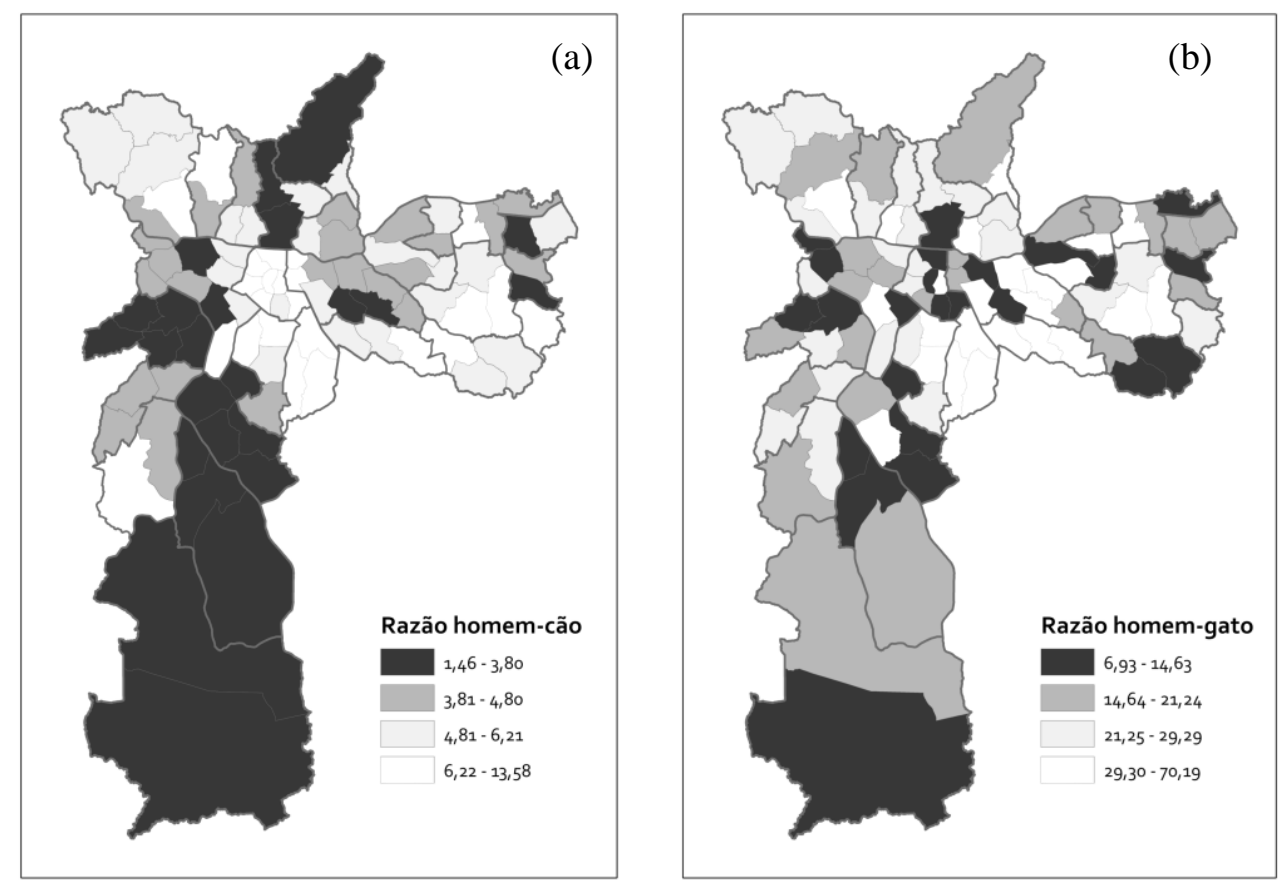

Figura 2. Mapas das razões entre populações humanas e animais ( $a=$ caninas e $b=$ felinas) domiciliadas no município de São Paulo, classificadas por quartil, 2011. 
Tabela 2. Distribuição da população de cães e gatos domiciliados nas tipologias de domicílios do município de São Paulo, 2011

\begin{tabular}{lrrrr}
\hline \multirow{2}{*}{ Tipologia de domicílio } & \multicolumn{2}{c}{ Cães } & \multicolumn{2}{c}{ Gatos } \\
\cline { 2 - 5 } & $\mathrm{N}$ & \multicolumn{1}{c}{$\mathrm{N}$} & \multicolumn{1}{c}{$\%$} \\
\hline Domicílio residencial & 2.410 .477 & 96,14 & 542.824 & 96,43 \\
Estabelecimento comercial & 71.544 & 2,85 & 13.865 & 2,46 \\
Domicílio residencial + estabelecimento comercial & 18.732 & 0,75 & 3.910 & 0,69 \\
Estabelecimento industrial & 6.347 & 0,25 & 2.147 & 0,38 \\
Domicílio residencial + estabelecimento industrial & 301 & 0,01 & 219 & 0,04 \\
Estabelecimento comercial + industrial & 0 & 0,00 & 0 & 0,00 \\
\hline Total & 2.507 .401 & 100,00 & 562.965 & 100,00 \\
\hline
\end{tabular}

Na cidade de São Paulo, há significativamente mais cães machos $(52,7 \%)$ que fêmeas $(47,3 \%)$. Há maior proporção de cães machos em áreas menos incluídas socialmente $(r=-0,20, \mathrm{P}=$ 0,046). Existe correlação positiva entre cães machos e objetivo de posse para guarda $(r=$ $0,25, \mathrm{P}=0,013)$. No entanto, não há correlação entre objetivo de posse para guarda e frequência de invasão domiciliar, nem tampouco entre invasão domiciliar e exclusão social. Ao contrário dos cães, para gatos, a frequência de fêmeas $(54,9 \%)$ é significantemente maior que a de machos $(45,1 \%)$. Diferentemente do que ocorre com os cães, não existe correlação entre gêneros de gatos e índice de exclusão social. A maior proporção de cães machos pode estar correlacionada à aversão dos proprietários às fêmeas, por apresentarem cio e, sem esterilização, crias. As proporções entre gêneros de cães e gatos são condizentes às encontradas por Paranhos (2002).

A idade média dos cães do município de São Paulo é de 4,99 anos (IC95\% = 4,90-5,09). As idades médias não diferem ao se compararem os gêneros: 4,97 (IC95\% = 4,83; 5,11) anos para fêmeas e 5,02 (IC95\% = 4,89; 5,16) anos para machos. A idade média de gatos é de 3,53 anos, significantemente menor quando comparada à dos cães. Ao se compararem os gêneros de gatos, não há diferença significativa das idades médias: 3,79 (IC95\% = 3,46; 4,11) anos para fêmeas e $3,24(\mathrm{IC} 95 \%=2,94 ; 3,54)$ anos para machos.

A proporção de domicílios com animais, segundo a espécie e a tipologia de domicílio, está representada na Tab. 3 .

Tabela 3. Proporção (\%) de domicílios com animais, segundo a espécie e a tipologia de domicílio no município de São Paulo, 2011

\begin{tabular}{|c|c|c|c|c|c|c|c|}
\hline & 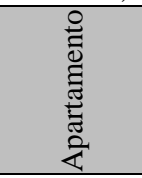 & 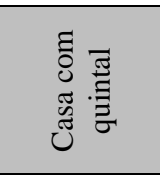 & 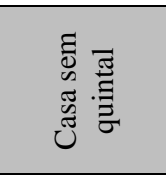 & 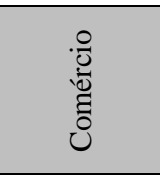 & 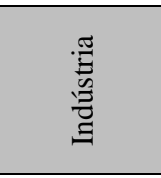 & 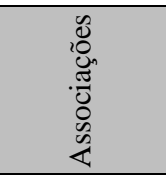 & 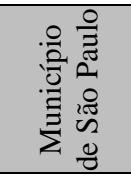 \\
\hline $\begin{array}{l}\text { Possuíam } \\
\text { animais (\%) } \\
\text { (IC95\%) }\end{array}$ & $\begin{array}{c}38,2 \\
(36-40,5)\end{array}$ & $\begin{array}{c}68,3 \\
(67,1-69,4)\end{array}$ & $\begin{array}{c}42,2 \\
(38,2-46,2)\end{array}$ & $\begin{array}{c}14,7 \\
(12,4-17,4)\end{array}$ & $\begin{array}{c}19,6 \\
(11,1-32,3)\end{array}$ & $\begin{array}{c}53,4 \\
(42,4-64,1)\end{array}$ & $\begin{array}{c}54,8 \\
(53,9- \\
55,7)\end{array}$ \\
\hline $\begin{array}{l}\text { Possuíam } \\
\text { cães (\%) } \\
\text { (IC95\%) }\end{array}$ & $\begin{array}{c}33,7 \\
(31,5-36)\end{array}$ & $\begin{array}{c}63,4 \\
(62,2-64,6)\end{array}$ & $\begin{array}{c}31,1 \\
(27,5-35)\end{array}$ & $\begin{array}{c}13 \\
(10,8-15,6)\end{array}$ & $\begin{array}{c}17,5 \\
(9,3-30,4)\end{array}$ & $\begin{array}{c}46,1 \\
(35,5-57,1)\end{array}$ & $\begin{array}{c}50 \\
(49,1- \\
50,9)\end{array}$ \\
\hline $\begin{array}{l}\text { Possuíam } \\
\text { gatos (\%) } \\
\text { (IC95\%) }\end{array}$ & $\begin{array}{c}5,7 \\
(4,6-7,1)\end{array}$ & $\begin{array}{c}12,9 \\
(12-13,8)\end{array}$ & $\begin{array}{c}16,2 \\
(13,3-19,5)\end{array}$ & $\begin{array}{c}2,5 \\
(1,7-3,7)\end{array}$ & $\begin{array}{c}5,5 \\
(1,5-18)\end{array}$ & $\begin{array}{c}13,8 \\
(7,5-24)\end{array}$ & $\begin{array}{c}10,6 \\
(10-11,3)\end{array}$ \\
\hline $\begin{array}{l}\text { Possuíam } \\
\text { ambos (\%) } \\
\text { (IC95\%) }\end{array}$ & $\begin{array}{c}1,2 \\
(0,6-2,4)\end{array}$ & $\begin{array}{c}8 \\
(7,4-8,7)\end{array}$ & $\begin{array}{c}5,1 \\
(3,5-7,4)\end{array}$ & $\begin{array}{c}0,8 \\
(0,4-1,6)\end{array}$ & $\begin{array}{c}3,3 \\
(0,5-19,9)\end{array}$ & $\begin{array}{c}6,5 \\
(2,5-15,6)\end{array}$ & $\begin{array}{c}5,8 \\
(5,3-6,3)\end{array}$ \\
\hline $\begin{array}{l}\text { Proporção } \\
\text { na amostra } \\
(\%) \\
(\%)\end{array}$ & 18,3 & 63,8 & 6,1 & 10,2 & 0,7 & 0,9 & --- \\
\hline
\end{tabular}


O número médio de cães em domicílio com cães é de 1,6 (IC95\% = 1,57; 1,63), e o de gatos em domicílios com gatos de 1,69 (IC95\% = 1,61; 1,77). A média de humanos em domicílios com animais é 4 (IC95\% = 3,91; 4,09), sendo significantemente maior que a média de humanos no total de domicílios (com e sem animais), estimada em 3,47 (IC95\% = 3,41; 3,53).

Mesmo apresentando razões homem:cão mais elevadas, como observado em estudo anterior (Dias, 2001), distritos essencialmente rurais, como Marsilac e Parelheiros, foram os únicos a exibir média superior de cães por domicílio, se comparados com a média do município.

A proporção de cães com acesso à rua é de 64,4\% (IC95\% = 63,3\%; 65,5\%), significativamente maior que a de gatos, estimada em 42,5\% (IC95\% = 39,6\%; 45,5\%). $\mathrm{Na}$ maioria dos domicílios $(52,5 \%)$, os animais (cães e gatos) vivem ou têm acesso ao quintal. Quanto mais incluídos socialmente, os DA apresentam menor frequência de domicílios com animais mantidos em quintais $(r=-0,36, \mathrm{P}<$ 0,001). Quanto maiores as frequências de manutenção de animais em quintais, menores as razões homem:cão $(r=-0,31, \mathrm{P}=0,002)$. Para gatos, não ocorre o mesmo fato. Cães e gatos vivem ou têm acesso ao interior de $27,4 \%$ dos domicílios, no município. Quanto maior a frequência de manutenção de animais no interior dos domicílios, menor a exclusão social $(r=0,52$, $\mathrm{P}<0,001)$. Evidentemente, há correlação positiva entre manutenção de animais dentro do domicílio e apartamentos $(r=0,72, \mathrm{P}<0,001)$. Constatou-se uma frequência significativa de domicílios $(6,5 \%)$ que mantêm seus animais presos em corrente. Quanto mais elevada esta frequência, maior a exclusão social $(r=-0,75, \mathrm{P}<$ $0,001)$. Uma pequena parcela dos proprietários $(1,4 \%)$ mantém seus animais em canis ou gatis. Os canis e gatis são mais frequentes em áreas periféricas da cidade, onde ainda há estoque imobiliário disponível. Quanto mais elevada a frequência de manutenção em canis ou gatis, maior a exclusão social $(r=-0,28, \mathrm{P}=0,006)$. Finalmente, o local de manutenção de animais menos frequente é a rua (1\%). Quanto mais elevada a frequência de manutenção dos animais na rua, maior a exclusão social $(r=-0,51$, $\mathrm{P}<0,001)$. Esta forma de manutenção de animais ocorre, com maior frequência, na periferia da cidade. Uma proporção de $11,2 \%$ dos animais tem acesso a mais de um local de manutenção. De fato, 6,2\% (IC95\% = 5,7\%; 6,8\%) dos animais têm acesso tanto ao interior do domicílio quanto ao quintal. Além disso, uma proporção de $1,5 \%(\mathrm{IC} 95 \%=1,3 \% ; 1,9 \%)$ dos animais tem acesso ao quintal e à rua, e uma proporção de $1,1 \%$ (IC95\% $=0,9 \% ; 1,4 \%$ ) dos animais tem acesso tanto ao interior do domicílio quanto à rua.

É preocupante o grande número de animais que têm acesso irrestrito à rua, ou seja, sem restrição de movimento. Animais nesta situação podem vagar livremente nas ruas, ocasionando, por exemplo, invasão de domicílios, atropelamentos e, eventualmente, agressão a pessoas e a outros animais domésticos. O contato com outros animais também pode levar à transmissão de doenças, muitas delas zoonóticas. Esta situação ocorre mais frequentemente na periferia da cidade.

Ter animais para companhia prevalece como principal objetivo de posse $(81,5 \%)$ se comparado a ter animais para guarda $(11,8 \%)$. Não há correlação das razões homem:cão e homem:gato com o objetivo de posse para companhia, nem tampouco para guarda. Apesar disso, quanto maior a exclusão social, menor a proporção de proprietários que têm animais porque gostam $(r=0,27, \mathrm{P}=0,008)$ e maior a proporção de proprietários que têm animais por dó $(r=-0,38, \mathrm{P}<0,001)$. Não há correlação de exclusão social com as demais motivações de posse (necessidade e presente), nem tampouco com objetivos de posse para guarda ou companhia. Em domicílios com dois ou mais animais, foi comum observar uma sobreposição dos objetivos de posse. Esta situação ocorreu em $6,6 \%$ dos domicílios.

A principal motivação de posse de animais é gostar de animais (79,3\%). As demais motivações foram menos expressivas: ganhar de presente $(8,2 \%)$, necessidade $(3,3 \%)$ e dó $(2,8 \%)$. As associações entre motivações de posse totalizaram $6,4 \%$. Tanto para cães quanto para gatos, não há correlação entre o número de animais por pessoa e as diferentes motivações de posse. Quanto mais elevada a proporção de proprietários que gostam de seus animais, maior a frequência de objetivo de posse para companhia $(r=0,32, \mathrm{P}=0,002)$ e menor a frequência de objetivo de posse para guarda 
$(\mathrm{r}=-0,24, \mathrm{P}=0,021)$. Por outro lado, quanto maior a proporção de motivação de posse por necessidade, maior a frequência de objetivo de posse para guarda $(r=0,43, \mathrm{P}<0,001)$.

A proporção de cães adotados (73,9\%) é significantemente maior que a de cães comprados (26,1\%), no município. Quanto maior a frequência de cães adotados, maior a exclusão social $(r=-0,71, \mathrm{P}<0,001)$. Além disso, há uma correlação positiva entre a frequência de domicílios com cão e a frequência de cães adotados $(r=0,36, \mathrm{P}<0,001)$. Assim como para os cães, a proporção de gatos adotados $(91,3 \%)$ é significantemente maior que a de gatos comprados $(8,7 \%)$, no município como um todo. Também existe correlação desta variável com exclusão social $(r=-0,23, \mathrm{P}=0,023)$, porém mais discreta se comparada com o mesmo resultado para cães.

Uma proporção de $3,3 \%$ dos proprietários informou intenção de aumentar o número de animais no domicílio. Paralelamente, 5,2\% dos proprietários informaram intenção de diminuir o número de animais. Finalmente, a maioria dos proprietários $(91,5 \%)$ declarou intenção de manter o número de animais. Não há correlação das razões homem:cão e homem:gato e a intenção de alterar o número de animais no domicílio. Por outro lado, quanto maior a exclusão social, a disposição das pessoas em diminuir o número de animais $(r=-0,31, \mathrm{P}=$ $0,002)$ é mais frequente que aumentar $(r=-0,22$, $\mathrm{P}=0,03)$. Quanto menor a exclusão social, maior a disposição em manter o número atual de animais $(r=0,24, \mathrm{P}=0,017)$.

A proporção de animais que são dados de presente é elevada, levantando dúvidas quanto ao tratamento prestado a estes animais e se estes podem, potencialmente, ser abandonados. Aliado a este fato, nos DA onde a proporção de proprietários com intenção de diminuir o número de animais é elevada, é provável que ocorra o abandono de animais com maior frequência.

Durante as entrevistas, não foi perguntada a raça dos animais. O elevado grau de subjetividade envolvido na resposta dos proprietários e os cruzamentos de raças produziriam vieses incontroláveis durante a análise. É possível, no entanto, propor uma correlação entre a proporção de animais comprados e animais com raça definida.

\section{CONCLUSÕES}

A guarda de cães e gatos é influenciada por fatores culturais, tais quais forma de ocupação do espaço, tipo de domicílio e nível de atenção prestada aos animais. A alta densidade populacional dessas espécies exige a adoção de estratégias oficiais que visem minimizar impactos ambientais e sanitários. Há elementos que demonstram a melhoria de indicadores associados à posse responsável, que devem ser fomentados na forma de políticas públicas e ações de educação em saúde.

\section{AGRADECIMENTOS}

Os autores agradecem ao Prof. Dr. Fernando Ferreira, ao Prof. Dr. Marcos Amaku, ao Prof. Dr. José Soares Ferreira Neto, à Aline Gil Alves Guilloux, à Carolina Ballarin Zetun, à Fernanda Ywasaki, a Renato Akio Ogata, além dos médicos veterinários, biólogos e aos 117 agentes de apoio das Supervisões de Vigilância em Saúde (SUVIS) que participaram deste trabalho.

\section{REFERÊNCIAS}

ALVES, M.C.G.P.; MATOS, M.R.; REICHMAN, M.L. et al. Dimensionamento da população de cães e gatos no interior do Estado de São Paulo. Rev. Saúde Publ., v.39, p.891-897, 2005.

BECK, A.M. The ecology of stray dogs. West Lafayette: Purdue University, 1973. 98p.

BRASIL. Prefeitura do Município de São Paulo. Comunicado SMS no 87, de 15 de agosto de 2002. Adequação do Sistema Municipal de Saúde às Subprefeituras. Diário Oficial [do Município de São Paulo]. São Paulo, SP, ano 47, n.143, 15 ago 2002.

DIAS, R.A. Emprego de sistemas de informação geográfica no controle da raiva canina. 2001. 84f. Dissertação (Mestrado em Epidemiologia Experimental e Aplicada às Zoonoses) - Faculdade de Medicina Veterinária e Zootecnia, Universidade de São Paulo, SP.

DIAS, R.A.; GARCIA, R.C.; SILVA, D.F. et al. Estimativa de populações canina e felina domiciliadas em zona urbana do Estado de São Paulo. Rev. Saúde Pública. v.38, p.565-570, 2004. 
FAVORETTO, S.R.; CARRIERI, M.L.; CUNHA, S.E.M. et al. Antigenic typing of brazilian rabies virus samples isolated from animals and humans, 19892000. Rev. Inst. Med. Trop., v.44, p.91-95, 2002.

FOLHA de São Paulo. DNA Paulistano. São Paulo: Publifolha, 2009. 392p.

FUNDAÇÃO Sistema Estadual de Análise de DadosSEADE. Informações dos distritos da capital. São Paulo: SEADE, 2007. Disponível em: <www.seade.gov.br/produtos/distritos/imp.php>. Acessado em: 26 mar. 2009.

GRISI-FILHO, J.H.H.; AMAKU, M.; DIAS, R.A. et $a l$. Uso de sistemas de informação geográfica em campanhas de vacinação contra a raiva. Rev. Saúde Publica, v.42, p.1005-1011, 2008.

IBGE-Instituto Brasileiro de Geografia e Estatística. Censo populacional de 2000 [CD-Rom]. Rio de Janeiro: IBGE, 2000.

MACPHERSON, C.N.L.; MESLIN, F.X.; WANDELER, A.I. Dogs, zoonoses and public health. New York: CABI Publishing, 2000. 382p.

MAGNABOSCO, C. População domiciliada de cães e gatos em São Paulo: perfil obtido através de um inquérito domiciliar multicêntrico. $2006.98 \mathrm{f}$. Dissertação (Mestrado em Saúde Pública) - Faculdade de Saúde Pública, Universidade de São Paulo, SP.

NUNES C.M.; MARTINES, D.A.; FIKARIS, S. et al. Avaliação da população canina da zona urbana do município de Araçatuba, São Paulo, SP, Brasil. Rev. Saúde Publ., v.31, p.308-309, 1997.
PARANHOS N.T. Estudo das populações canina e felina em domicílio, município de São Paulo, 2001. 2002. 83f. Dissertação (Mestrado em Saúde Pública) Faculdade de Saúde Pública, Universidade de São Paulo, SP.

PLAUT, M.; ZIMMERMANN, E.M.; GOLDSTEIN, R.A. Health hazards to humans associated with domestic pets. Annu. Rev. Public. Health., v.17, p.221245, 1996

SISTEMA de Informação de Agravos de NotificaçãoSINAN. Relatório. Brasília: SINAN, 2009. Disponível em: <http://covisa.prodam/cgi-bin/deftohtm.exe? SINANNET/AntirabNET.def $>$. Acessado em: 05 mar. 2009.

SPOSATI, A.O. Mapa da exclusão/inclusão social da Cidade de São Paulo. São Paulo: Educ, 1996. 126p.

THOMAS, K. $O$ homem $e$ o mundo natural: mudanças na atitude em relação às plantas e aos animais (1500-1800). São Paulo: Companhia das Letras, 1988. 544p.

THRUSFIELD, M. Veterinary Epidemiology. 3nd ed. Oxford: Blackwell Science, 2007. 584p.

WORLD Health Organization-WHO. Guidelines for dog population management. Geneva: WHO, 1990. $116 \mathrm{p}$. 